\title{
Role of sublimation and riming in the precipitation distribution in the Kananaskis Valley, Alberta, Canada
}

\author{
Émilie Poirier $^{1}$, Julie M. Thériault ${ }^{1}$, and Maud Leriche ${ }^{1,2}$ \\ ${ }^{1}$ Centre ESCER, Departement of Earth and Atmospheric Sciences, Université du Québec à Montréal, \\ Montréal, Québec, Canada \\ ${ }^{2}$ Laboratoire d'Aérologie, CNRS, Université Paul Sabatier, Toulouse, France
}

Correspondence: Julie M. Thériault (theriault.julie@uqam.ca)

Received: 29 January 2019 - Discussion started: 13 February 2019

Revised: 20 June 2019 - Accepted: 11 July 2019 - Published: 2 October 2019

\begin{abstract}
The phase of precipitation and its distribution at the surface can affect water resources and the regional water cycle of a region. A field project was held in MarchApril 2015 on the eastern slope of the Canadian Rockies to document precipitation characteristics and associated atmospheric conditions. During the project, $60 \%$ of the particles documented were rimed in relatively warm and dry conditions. Rain-snow transitions also occurred aloft and at the surface in sub-saturated conditions. Ice-phase precipitation falling through a saturated atmospheric layer with temperatures $>0{ }^{\circ} \mathrm{C}$ will start melting. In contrast, if the melting layer is sub-saturated, the ice-phase precipitation undergoes sublimation, which increases the depth of the rain-snow transition. In this context, this study investigates the role of sublimation and riming in precipitation intensity and type reaching the surface in the Kananaskis Valley, Alberta, during March-April 2015. To address this, a set of numerical simulations of an event of mixed precipitation observed at the surface was conducted. This event on 31 March 2015 was documented with a set of devices at the main observation site (Kananaskis Emergency Services, KES), including a precipitation gauge, disdrometer, and micro rain radar. Sensitivity experiments were performed to assess the impacts of temperature changes from sublimation and the role of the production of graupel (riming) aloft in the surface precipitation evolution. A warmer environment associated with no temperature changes from sublimation leads to a peak in the intensity of graupel at the surface. When the formation of graupel is not considered, the maximum snowfall rate occurred at later times. Results suggest that unrimed snow reaching the surface is formed on the western flank and is advected east-
\end{abstract}

ward. In contrast, graupel would form aloft in the Kananaskis Valley. The cooling from sublimation and melting by rimed particles increases the vertical shear near KES. Overall, this study illustrated that the presence of graupel influenced the surface evolution of precipitation type in the valley due to the horizontal transport of precipitation particles.

\section{Introduction}

The phase of precipitation can lead to major disasters such as the 2013 Calgary flooding event (Milrad et al., 2015; Liu et al., 2016). In this particular event, the heavy rain generated rainfall runoff at low and mid elevations, but it was supplemented by rain-on-snow runoff at high elevations due to a late-lying snowpack (Pomeroy et al., 2016). The rain on snow caused by a higher than usual $0^{\circ} \mathrm{C}$ isotherm was one of the many factors that led to this catastrophic flooding.

The rain-snow boundary, also called the precipitation transition region, is the area characterized by mixed precipitation bounded by only rain and only snow at the surface and aloft, respectively. The top of the boundary corresponds to the top of the melting layer aloft, which is associated with a maximum reflectivity value called the radar bright band (Fabry and Zawadzki, 1995), and the base of the boundary is when all snow/graupel has melted into rain. Marwitz (1983, 1987) studied these rain-snow transitions in mountainous areas using observations over the Sierra Nevada, USA. They observed that the height of the radar bright band, which is associated with the top of the precipitation transition region, decreased by $400-600 \mathrm{~m}$ while approaching the mountain 
barrier, corresponding to a lower $0{ }^{\circ} \mathrm{C}$ isotherm near the barrier. Simulations were also used to study the lowering of the rain-snow boundary on a mountain windward slope (Minder et al., 2011). These simulations identified two physical mechanisms influencing the location of the rain-snow boundary along the mountainside: cooling by melting of solid icephase particles and adiabatic cooling of rising air. The distance associated with complete melting of ice-phase precipitation was also an important factor.

In a saturated environment, diabatic cooling due to melting of ice-phase precipitation falling in a warm layer $\left(T>0{ }^{\circ} \mathrm{C}\right)$ can lead to a change in the valley wind flow. This was observed in the Toce River valley in the Italian Alps during the Mesoscale Alpine Program (MAP, Steiner et al., 2003) and during the 2010 Vancouver Olympics in the Whistler area (Thériault et al., 2012, 2015). However, Zängl (2007) used numerical 3-D simulations to demonstrate that the cooling by melting of snow was of less importance in creating the down-valley flow for the same event as Steiner et al. (2003) because of the impact of cooling associated with sublimation.

Because ice-phase precipitation melts only when the wetbulb temperature is $>0{ }^{\circ} \mathrm{C}$, it can reach the surface at abovefreezing temperature in a dry environment. For example, a few studies reported ice-phase precipitation at surface air temperatures of $4-6{ }^{\circ} \mathrm{C}$ (e.g. Matsuo et al., 1981; Harder and Pomeroy, 2013). Few studies addressing the effects of cooling by sublimation in winter storms exist, especially in mountainous regions. For instance, Clough and Franks (1991) examined the evaporative processes in frontal and stratiform precipitation. They showed that sublimation of ice particles was an efficient thermodynamic process. Parker and Thorpe (1995) studied the role of snow sublimation in frontogenesis and showed that the cross-frontal flows in the vicinity of the sublimation were strongly modified, and a mesoscale downdraft was produced below the synoptic frontal surface. Barth and Parsons (1996) highlighted that sublimation of snow and rimed particles played an important role in the modelled evolution of a narrow cold-frontal rain band.

Few studies have examined precipitation features in northern Canada in relatively dry areas. Burford and Stewart (1998) suggested that sublimation was the main process responsible for relatively low precipitation amounts observed at Inuvik and Tuktoyaktuk (Northwest Territories). Furthermore, Stewart et al. (2004) examined precipitation events at Fort Simpson (Northwest Territories) and found that hydrometeors were mainly single crystals and aggregates. The absence of rimed particles could explain the low precipitation amounts as single crystals and aggregates are more likely to sublimate while falling to the surface. In contrast, Henson et al. (2011) and Fargey et al. (2014) characterized precipitation types over Baffin Island, Nunavut, showing that rimed particles, aggregates, and snow pellets were very common even during light precipitation events. They suggested that the development of rimed and large particles increased their likelihood of reaching the surface through the drier sub-cloud layer.

In this context, to better understand the processes leading to surface precipitation on the lee side of the Canadian Rockies, a field campaign was held during March-April 2015 in the Kananaskis Valley, Alberta (Fig. 1). The goal of this field campaign was to document precipitation and associated weather conditions in that region (Thériault et al., 2018). Given the importance of precipitation phase in this area, there is a need to improve our understanding of the physical processes leading to rain-snow transition in these particular sub-saturated areas. The goal of this study is to investigate the role of sublimation and riming in the precipitation intensity and types reaching the surface in the Kananaskis Valley, Alberta. To address this, numerical simulations using the Weather Research and Forecasting (WRF) model (Skamarock and Klemp, 2008) were conducted. A welldocumented case study associated with mixed precipitation reaching the surface in the Kananaskis Valley was chosen from the 2015 field campaign mentioned above. After verifying that the model is able to represent this observed case study, numerical simulations are used to investigate physical processes producing the distribution of precipitation in the Kananaskis area.

This paper is structured as follows. Section 2 provides an overview of the field project and describes the case study used in this paper. The methodology, including the model configuration, the sensitivity experiments, and the data analysis, is explained in Sect. 3. Results from the control simulation, the role of sublimation, and the formation of rimed snow are summarized in Sects. 4-6, respectively. Finally, a summary and conclusion are given in Sect. 7.

\section{Overview of the case study}

During the Alberta Field Project held in the Kananaskis Valley in March-April 2015, a total of 17 precipitation events were documented (Thériault et al., 2018). These were associated with rain or snow only, as well as a mixture of precipitation. Ice-phase precipitation was reported at the surface at temperatures up to $9{ }^{\circ} \mathrm{C}$ but in very dry conditions ( $45 \%$ relative humidity), also noted by Harder and Pomeroy (2013), and most of them were rimed $(\sim 60 \%)$.

Most of the observations were collected at the Kananaskis Emergency Services (KES) site located a few kilometres south-east of the Nakiska ski area (NAK) and about $15 \mathrm{~km}$ south of the Barrier Lake research station (BAR) (Fig. 1), and are now detailed. To characterize the atmospheric conditions (temperature and relative humidity) aloft, a sounding system was used and balloons were launched every $3 \mathrm{~h}$ during precipitation events. The precipitation layer aloft was characterized using a Micro Rain Radar (MRR2, Klugmann et al., 1996). MMR2 gives the temporal evolution of the vertical profile of the reflectivity and Doppler velocity; note that 


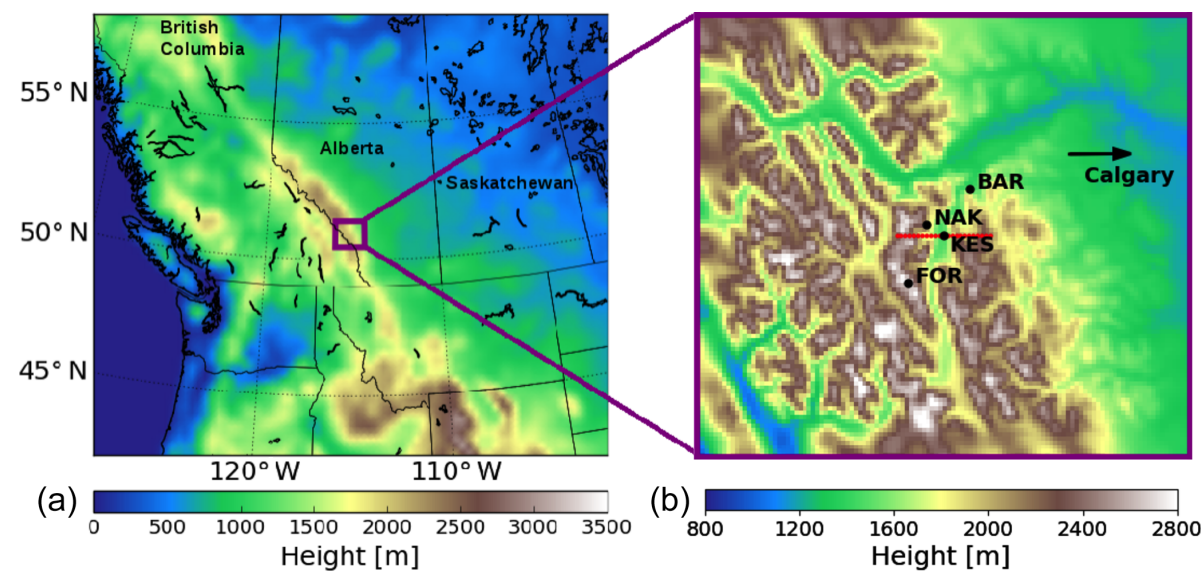

Figure 1. Area of interest (a) and $1 \mathrm{~km}$ mesh domain (b) used for the numerical simulations with the WRF model. BAR stands for the Barrier Lake research station, NAK for the Nakiska ski area, KES for the Kananaskis Emergency Services site, and FOR for Fortress Mountain. Red line in (b) indicates the position of the cross section used in Figs. 6 and 8.

this measurement is affected by the signal attenuation due to e.g. the bright band (Matrosov et al., 2008). A GEONOR weighing precipitation gauge (Rasmussen et al., 2011) was used to measure the liquid equivalent amount of precipitation. An optical disdrometer, OTT Parsivel 2 (Battaglia et al., 2010), was used to characterize the type of hydrometeor by measuring the fall speed and diameter of precipitation particles. The precipitation types were automatically diagnosed using the Ishizaka et al. (2013) method and the optical disdrometer data (Thériault et al., 2018). Manual observations of weather conditions including precipitation types were also reported in a systematic manner. The manual method is more precise because one can estimate the degree of riming and the exact crystal types. The Ishizaka et al. (2013) method gives a good idea of the degree of riming, but it is not possible to diagnose the type of ice crystal because of the bin sizes. Basic meteorological measurements were also available (pressure, wind speed and direction, temperature, dew-point temperature). Finally, vertical profiles of basic meteorological features were obtained using a Kestrel attached to a ski pole and a GPS (Thériault et al., 2014) to characterize rain-snow transitions at NAK and at Fortress Mountain (FOR). Further details about the field campaign are given in Thériault et al. (2018).

The well-documented weather event that occurred on 31 March 2015 was chosen for this study for three main reasons. First, all of the weather instruments deployed at KES were operational. Second, a mixture of precipitation types and phase transition in sub-saturated conditions occurred at the surface, so it is possible to investigate the role of melting and sublimation of ice hydrometeors. Finally, detailed measurements on the height and width of the transition have been conducted along FOR using the "car-sonde" technique described in Thériault et al. (2018).
On 31 March 2015, a weather event associated with a rain-snow boundary along the mountainside occurred in the Kananaskis Valley. The sounding launched at 21:00 UTC shows sub-saturated conditions near the surface at the KES site (Fig. 2). The MMR2 reflectivity profiles (Fig. 3a) show precipitation reaching the surface for about $2 \mathrm{~h}$. The radar reflectivity bright band $(>30 \mathrm{dBZ})$ is located at the elevation where ice-phase precipitation started to melt (Fig. 3a). Measurements along FOR using the "car-sonde" technique indicated that the top of the rain-snow boundary was at $1750 \mathrm{~m}$ a.s.l. The rain-snow transition is located about $200 \mathrm{~m}$ below the $0{ }^{\circ} \mathrm{C}$ isotherm, which confirms that ice-phase precipitation was not melting until the level associated with a wet-bulb temperature, $T_{\mathrm{w}},>0{ }^{\circ} \mathrm{C}$, was reached (Harder and Pomeroy, 2013).

The surface temperature at 21:00 UTC 31 March 2015 decreases from 12 to $3{ }^{\circ} \mathrm{C}$, whereas the relative humidity increases up to the onset of precipitation from around $25 \%$ to around $75 \%$ (Fig. 3c). Wind speed is generally weak throughout the precipitation event, with variable directions (Fig. 3d). Manual observations at the KES site show that light rain started at 20:30 UTC 31 March 2015, changing to a mixture of rain, snow, and graupel between about 21:50 and 22:15 UTC, and then to a brief period of only rain (Fig. 3f). The automatic diagnostic of precipitation types supports this.

\section{Description of the simulations}

\subsection{Model configuration}

Three-dimensional (3-D) simulations are performed using the WRF model, version 3.7.1 (Skamarock and Klemp, 2008), with initial and boundary conditions provided by the North American Regional Reanalysis (NARR) data from the National Center for Environmental Prediction (NCEP) 


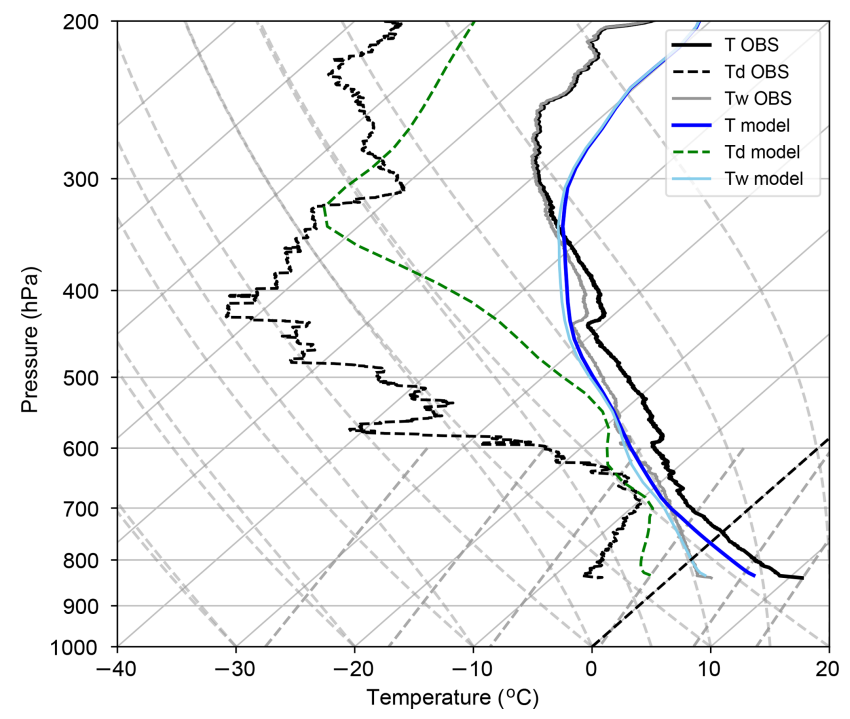

Figure 2. Vertical profiles of air temperature ( $T$, solid line), dewpoint temperature $\left(T_{\mathrm{d}}\right.$, dashed line), and wet-bulb temperature $\left(T_{\mathrm{W}}\right.$, light colour) at 21:00 UTC 31 March 2015 at the KES site. The measurement (OBS) and the control simulation (model) described in Sect. 3.1 are represented by blue and black/grey lines, respectively.

(Mesinger et al., 2006). The boundary conditions' forcing is done every $3 \mathrm{~h}$. Two-way nesting with four nested grids (27, 9,3 , and $1 \mathrm{~km}$ ) is used to perform high-resolution simulations over the Kananaskis Valley. The high-resolution domain is shown in Fig. 1; it has $118 \times 106$ grid points. The following analysis of simulated results will focus only on outputs from the high-resolution domain. The control run (CTR hereafter) and the sensitivity tests are conducted with the two-moment bulk microphysics scheme of Milbrandt and Yau (2005a, b) to predict cloud and precipitation.

Other parameterizations used in the simulations include the Rapid Radiative Transfer Model (RRTMG) with the Monte Carlo independent column approximation (MCICA) method of random cloud overlap (Iacono et al., 2008) for longwave and shortwave radiation. Also, the Noah Land Surface Model (Tewari et al., 2004) with soil temperature and moisture in four layers, fractional snow cover, and frozen soil physics is used. The planetary boundary layer is parameterized in the simulations with the Yonsei University scheme, which uses the non-local $K$ approach with an explicit entrainment layer and a parabolic $K$ profile in the unstable mixed layer, where $K$ is the vertical diffusion coefficient (Hong et al., 2006). Cumulus parameterization is used on the coarser grid only $(27 \mathrm{~km})$ with the Kain-Fritsch scheme (Kain, 2004).

To have the maximum number of vertical levels within the melting layer, 56 vertical levels are used where the grid spacing varies from 50 to $320 \mathrm{~m}$ in the first $2 \mathrm{~km}$ and is between 320 and $340 \mathrm{~m}$ at higher levels. The simulation on the coarser grids $(27,9$, and $3 \mathrm{~km})$ starts at 15:00 UTC 31 March 2015, $3 \mathrm{~h}$ prior to the higher-resolution grid $(1 \mathrm{~km})$, which starts at 18:00 UTC 31 March 2015. The simulations are integrated for a total of 12 and $9 \mathrm{~h}$, respectively. The time step used is $90 \mathrm{~s}$ on the coarser grid $(27 \mathrm{~km})$, decreasing with a ratio of 3 between each nested grid to $3.33 \mathrm{~s}$ on the higher-resolution grid $(1 \mathrm{~km})$.

\subsection{Description of the microphysics scheme and modifications}

The two-moment microphysics scheme predicts the mass mixing ratio and the total number concentration of the inverse exponential size distribution of six hydrometeor categories: cloud droplets, rain, ice crystals, snow, graupel, and hail. Each category is described by an assumed massdiameter relationship and an associated fall speed. The evolution of clouds and precipitation is based on many microphysical processes that are mainly divided into cold and warm processes in the microphysics scheme. In this study we focus on the sublimation and melting of ice, snow, and graupel, as well as the impact of the presence of graupel. This last process includes the collision/coalescence of ice crystals and snow with cloud droplets or raindrops leading to rimed particles. This parameterization differs among bulk microphysics schemes. For example, Milbrandt and Yau (2005a, b) follow Murakami (1990) to parameterize the snow-graupel conversion. It is based on the rate of collection of snow/ice with cloud droplets as well as vapour deposition. The change from the snow category to graupel category involves a sharp increase in density (100 to $\left.400 \mathrm{~kg} \mathrm{~m}^{-3}\right)$ and, in turn, an increase in the fall velocity $\left(\sim 1\right.$ to $\left.3 \mathrm{~m} \mathrm{~s}^{-1}\right)$. Hence, the mass of snow can increase aloft without falling faster until it is converted into graupel. Pre-defined hydrometeor categories are a limitation of bulk microphysics schemes. A more detailed description of the conversion process as well as all processes is given in Milbrandt and Yau (2005a, b).

Since the area of interest for this study is located in a subsaturated environment, the scheme is modified to allow snow to sublimate at all temperatures. In the original Milbrandt and Yau (2005a, b) two-moment scheme, snow sublimation can only occur when the temperature is $<0^{\circ} \mathrm{C}$, while graupel can sublimate at all temperatures. Some modifications were made to this original scheme (Poirier, 2017). Given that graupel can sublimate at temperatures $>0{ }^{\circ} \mathrm{C}$, the same equation was used for snow, which is

$\mathrm{QVD}_{\mathrm{vs}}=\frac{1}{\mathrm{AB}_{\mathrm{i}}}\left[2 \pi\left(S_{\mathrm{i}}-1\right) N_{0 \mathrm{~s}} \mathrm{VENT}_{\mathrm{s}}-\frac{L_{\mathrm{s}} L_{\mathrm{f}}}{K_{\mathrm{a}} R_{\mathrm{v}} T^{2}} \mathrm{QCL}_{\mathrm{cs}}\right]$,

where

$\mathrm{AB}_{\mathrm{i}}=\frac{L_{\mathrm{s}}^{2}}{K_{\mathrm{a}} R_{\mathrm{v}} T^{2}}+\frac{1}{\rho q_{\text {is }} \psi}$

is the thermodynamic function. Also, $S_{\mathrm{i}}$ is the saturation ratio with respect to ice, $N_{0 \mathrm{~s}}$ is the intercept parameter for 

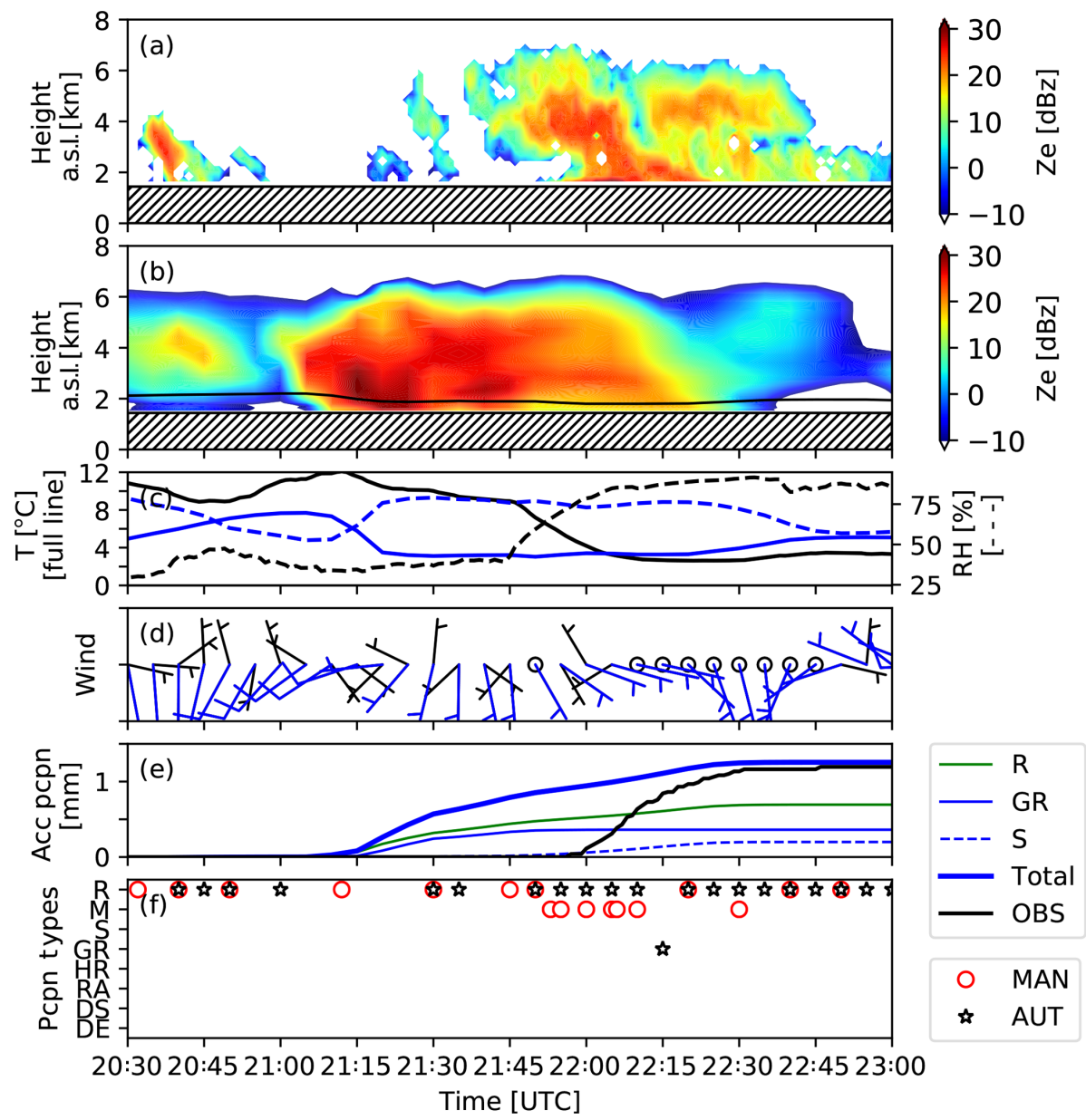

Figure 3. Atmospheric conditions and precipitation fields during the 31 March 2015 event at KES. (a) Reflectivity field measured by the Micro Rain Radar (MRR2) and (b) estimated by the model (CTR). Reflectivity values $>30 \mathrm{dBZ}$ are associated with the radar reflectivity bright band; (c) surface temperature $(T)$ and relative humidity $(\mathrm{RH})$ observed (black line) and simulated (blue line); (d) wind speed and direction using wind barbs, where observed is black and simulated is blue (an empty circle is wind speed rounded at 0 knots, and a short bar is rounded at 5 knots); (e) unadjusted liquid equivalent accumulated precipitation observed (black line, OBS) and simulated (bold blue line for total, green line for rain, thin blue line for graupel, and dashed blue line for snow), and (f) the type of precipitation observed manually (MAN) and automatically (AUT) at KES. These are rain $(R)$, graupel (GR), snow $(S)$, mixed precipitation $(M)$, heavily rimed snow (HR), rimed aggregates (RA), dry snow (DS), and dendrites (DE). Simulated results are for the CTL run. Adapted from Thériault et al. (2018).

snow, VENT $\mathrm{V}_{\mathrm{S}}$ is the mass-weighted ventilation factor (Ferrier, 1994), $K_{\mathrm{a}}$ is the thermal conductivity of air, $R_{\mathrm{v}}$ is the gas constant for water vapour, $T$ is the temperature of air, $\rho$ is the density of air, $q_{\text {is }}$ is the saturation vapour mixing ratio with respect to ice, and $\psi$ is the diffusivity of water vapour in air.

The sublimation rate equation was moved in the microphysics scheme so that snow and graupel sublimation are computed in the same conditions, at all air temperatures. The polysvp function was also corrected in the microphysics scheme to calculate the saturation vapour pressure properly at all temperatures. It has been fixed in the following version of WRF.

\subsection{Description of the sensitivity experiments}

The control simulation (CTR) is conducted using the modified microphysics and model configuration described in Sects. 3.1 and 3.2. To estimate the impact of temperature changes on the amount and types of precipitation at the surface, three sensitivity experiments were performed while neglecting the diabatic heating/cooling due to the precipitation phase transition and no graupel formation. The temperature tendency equation is 


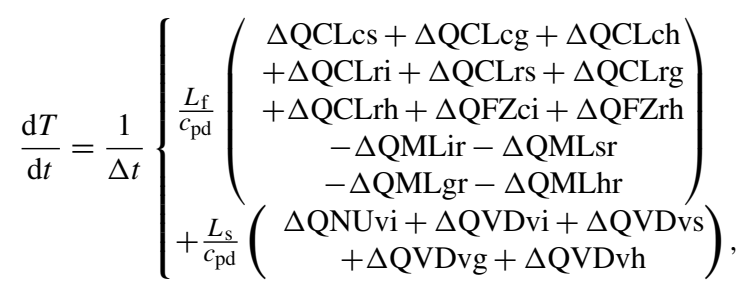

where $L_{\mathrm{f}}$ is the latent heat of fusion, $L_{\mathrm{S}}$ is the latent heat of sublimation, $c_{\mathrm{pd}}$ is the specific heat of dry air, and $Q$ is for the mixing ratio. The types of mixing ratios are denoted by "CL" for collection, "FZ" for freezing, "ML" for melting, "NU" for nucleation, and "VD" for diffusional growth (positive) or sublimation (negative), and the subscripts (c, r, i, s, g, $\mathrm{h}, \mathrm{v})$ represent cloud droplets, rain, ice, snow, graupel, hail, and water vapour.

The three key sensitivity experiments are the following.

1. NO_MLT. The diabatic cooling of melting snow and graupel was neglected. The terms QMLsr and QMLgr were set to zero in the temperature tendency equation (Eq. 1). Hence, snow and graupel were allowed to melt into rain, but no energy was extracted from the environment to melt the particles.

2. NO_SBL. The diabatic cooling of sublimation of snow and graupel was neglected. The negative portions of the terms QVDvs and QVDvg were set to zero in the temperature tendency equation (Eq. 1).

3. NO_GRPL. Since graupel often reached the surface at KES during the Alberta Field Project (Thériault et al., 2018), another simulation was performed. The initiation of graupel was suppressed by turning the production of graupel off (grpl_ON = false). It also ensured that there were no sources or sinks and, hence, no warming from the cloud droplets freezing on the solid particles (snow or/and ice) and no sublimation of graupel since none was produced.

\subsection{Data analysis}

The data are analysed in a systematic manner. First, the CTR simulation is compared to available observations such as wind speed and direction, temperature, relative humidity, height of the rain-snow transition, as well as precipitation amount and types collected during the field project. The time evolution of the mass content of ice crystals, cloud, rain, graupel, and snow is analysed at the grid point closest to the KES site. To analyse precipitation aloft at KES and across the Kananaskis Valley, a vertical cross section is plotted and the mass content of hydrometeors, as well as the vertical air motion, are investigated. Second, the CTR simulation is compared to the three sensitivity experiments: the simulation without the temperature change from melting of snow and graupel (NO_MLT), the simulation without the temperature change from sublimation (NO_SBL), and the simulation without graupel (NO_GRPL). Finally, the impact of wind direction and precipitation types formed aloft on the precipitation amounts and types reaching the surface is investigated.

\section{Analysis of the control run}

\subsection{Comparison with observations}

The CTR simulation is compared to observations to verify that atmospheric conditions are sufficiently well represented to use the simulations as a qualitative analysis tool of physical processes. The simulated liquid equivalent accumulated precipitation is compared to observations in Fig. 4. Comparison shows good agreement at KES and NAK but an overestimation by the model near FOR (Fig. 4d). The gradient of precipitation along the mountainside is well represented, showing that rain accumulated in the valley (Fig. 4c). Higher amounts of graupel (Fig. 4b) are produced at higher elevations where the conditions for riming are more favourable because of the presence of cloud droplets (Milbrandt and Yau, 2005a, b). Both observations and CTR simulation show that the precipitation amount accumulated at KES is relatively low during this event and dominated by rain (Fig. 4c) with snow at high elevations (Fig. 4a).

Concerning the general meteorological parameters, the CTR run shows similar patterns to the observations at KES (cf. Figs. 2 and 3). The vertical structures of the temperature and dew point are similar, but the model is mainly colder and moister than the observations. The wet-bulb temperature is, however, similar (Fig. 2), although the timing of the precipitation differs. The simulated and observed relative humidities are similar, and even if temperatures are different before the onset of precipitation, they reach similar values during the precipitation event (cf. Fig. 3c). The wind direction is highly variable, but both the simulation and observation have southerly components before the onset of precipitation, while the simulations exhibit slightly stronger winds during the event (cf. Fig. 3d). Ice-phase precipitation is simulated at temperatures $>0{ }^{\circ} \mathrm{C}$ in the Kananaskis area as reported during the field project. Precipitation amounts simulated at KES are very low and reach $1.3 \mathrm{~mm}$ during the simulated event, in agreement with observations (Fig. 3e).

The rain-snow boundary occurred at warmer temperatures than if the environmental conditions were saturated, and is reproduced between 21:00 and 22:30 UTC 31 March 2015, as measured by the "car-sonde" at FOR (Thériault et al., 2018), which varied from 1750 to $1830 \mathrm{~m}$. The simulated height of the melting layer at about $1600 \mathrm{~m}$ (Fig. 5e) corresponds to that measured by the MRR2 bright band (Fig. 3a). The reflectivity computed is higher than observations and it is difficult to discern the bright band near the surface because of the high-reflectivity fields probably produced by graupel (Fig. 3b). The comparison of Fig. 3e and f shows an agreement between the type of hydrometeors simulated and ob- 

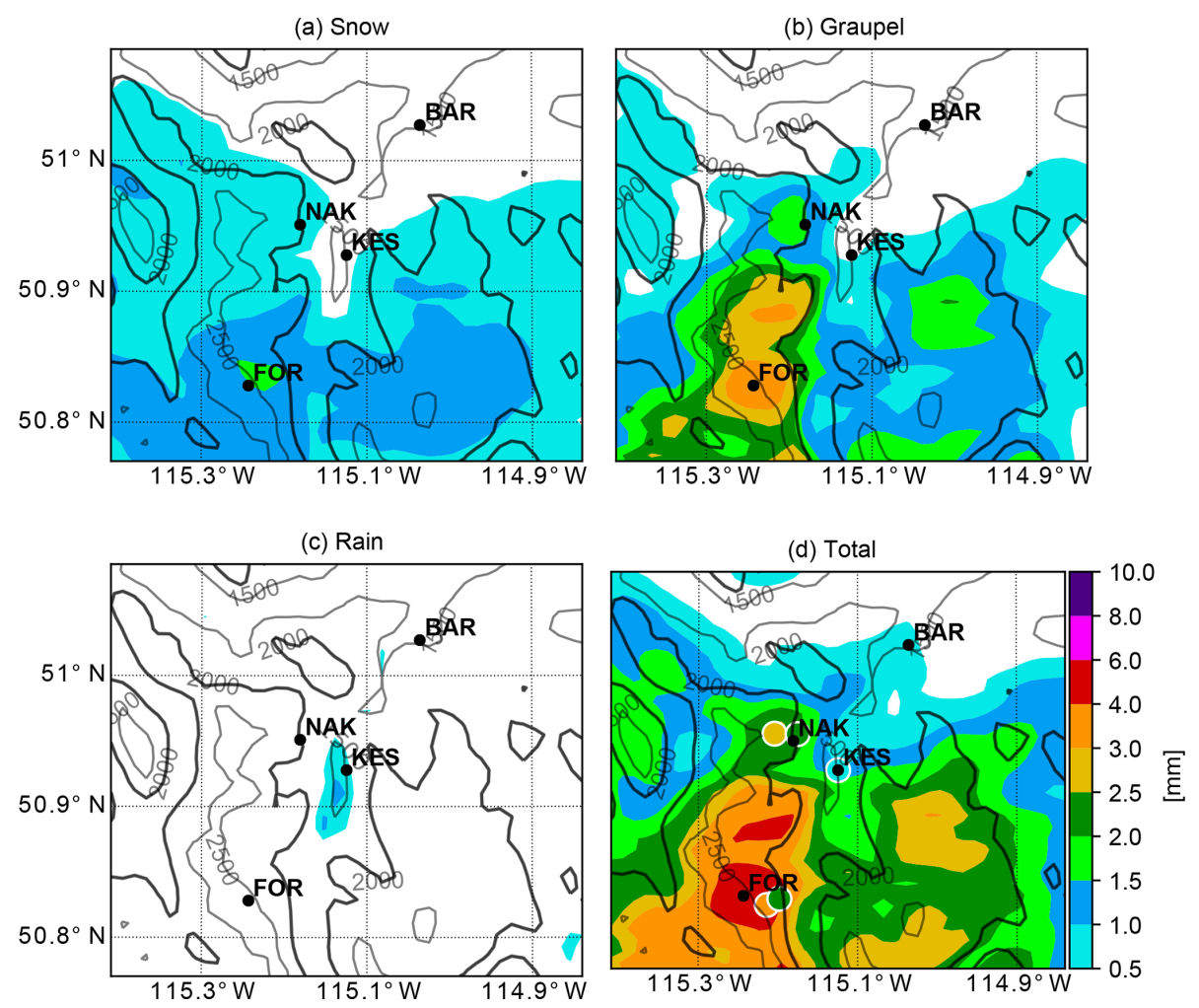

Figure 4. Simulated (a) unadjusted accumulated solid precipitation (mm) including (a) snow and (b) graupel, (c) rain, and (d) total accumulated precipitation between 20:00 UTC 31 March 2015 and 00:00 UTC 1 April 2015. The coloured circles in (d) are the observations at four locations. These are KES $(2.7 \mathrm{~mm})$, Nakiska $(2.2 \mathrm{~mm})$, Fortress $(3 \mathrm{~mm})$, and Barrier Lake Station $(0.8 \mathrm{~mm})$. Accumulated precipitation is in liquid equivalent. The black lines are the topography in metres.

served, with the predominance of rain and the presence of graupel. We notice that precipitation begins earlier in the simulation than in the observation (almost $1 \mathrm{~h}$ ), as shown in Fig. 3e and by the time lag between Fig. 3a and $b$.

In summary, the meteorology at KES is generally qualitatively well simulated during the precipitation event. This statement allows us to use the model to investigate the impact of microphysical processes on the phase and distribution of precipitation at the surface.

\subsection{Vertical distribution of hydrometeors}

The vertical structure of hydrometeors at KES is now investigated. The riming of ice crystals with cloud droplets at $6 \mathrm{~km}$ ASL is a minor source of graupel (Fig. 5a). The main source of graupel seems to be riming of snow with cloud droplets based on the order of magnitude mixing ratio of both snow and graupel (Fig. 5e, i, and m). Snow occurs aloft throughout the event, but only reaches the surface from 21:45 until 22:30 UTC at a precipitation rate of $\sim 0.5 \mathrm{~mm} \mathrm{~h}^{-1}$ as it sublimates before reaching the surface (Fig. 5q). Rain occurs simultaneously with graupel and snow at the surface throughout the event (Fig. 5q). It corresponds mainly to the type of precipitation reported in Fig. 3f.
The vertical cross section of hydrometeors when snow starts to reach the surface (21:45 UTC) is shown in Fig. 6 across the Kananaskis Valley. The maximum mass contents of ice crystals and cloud droplets aloft occurred on the windward side of mountain slopes (Fig. 6a and e) and are transported across the valley. The location of the maximum number of ice crystals corresponds to the elevation where snow is formed. At that level, ice crystals interact with cloud droplets to produce graupel aloft (Fig. 6i). Snow is transported eastward by the wind and sublimates (Fig. $6 \mathrm{~m}$ ). The upward air motion leads to the formation of ice crystals (Fig. 6a) and cloud droplets (Fig. 6e) aloft above the westward barrier, which are converted into snow and graupel and transported downstream (Fig. 6i and m). Clouds (both ice and liquid) and precipitation produced on the westward barrier $(-10 \mathrm{~km})$ are transported east of KES. Note that no hail was produced in the simulations.

The remaining analysis will focus on the microphysical processes near KES. In particular, the impact of sublimation and the occurrence of graupel on the formation and evolution of precipitation types and amounts, as well as the wind field, are investigated. 

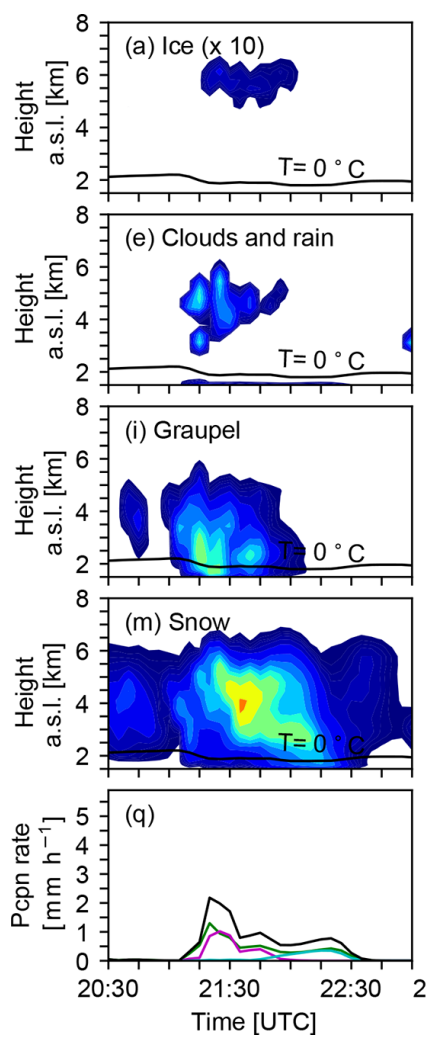
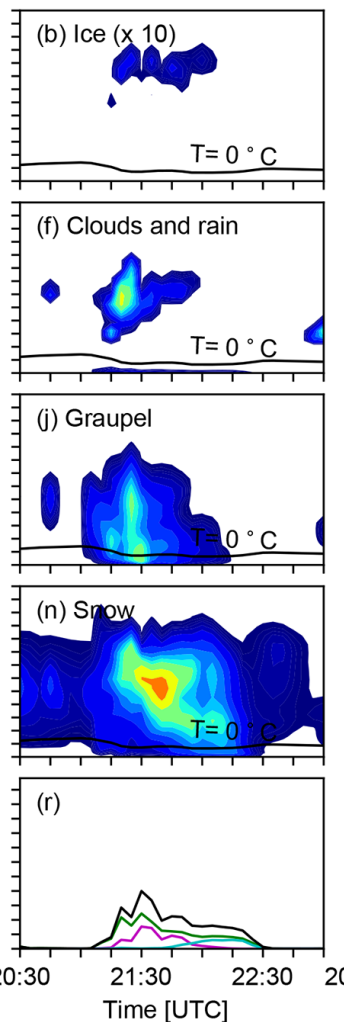
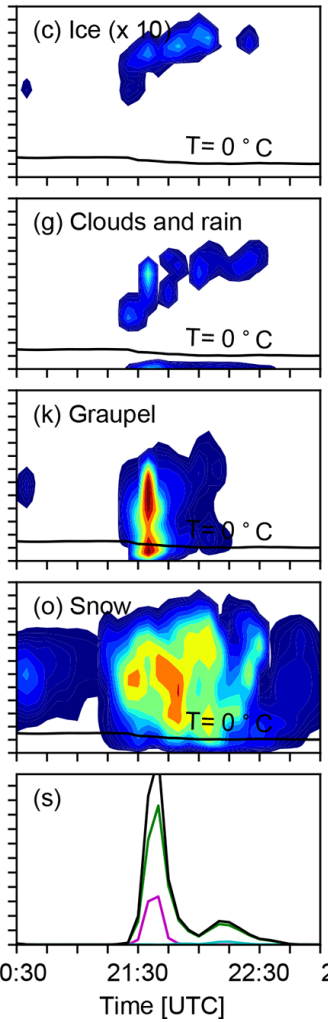

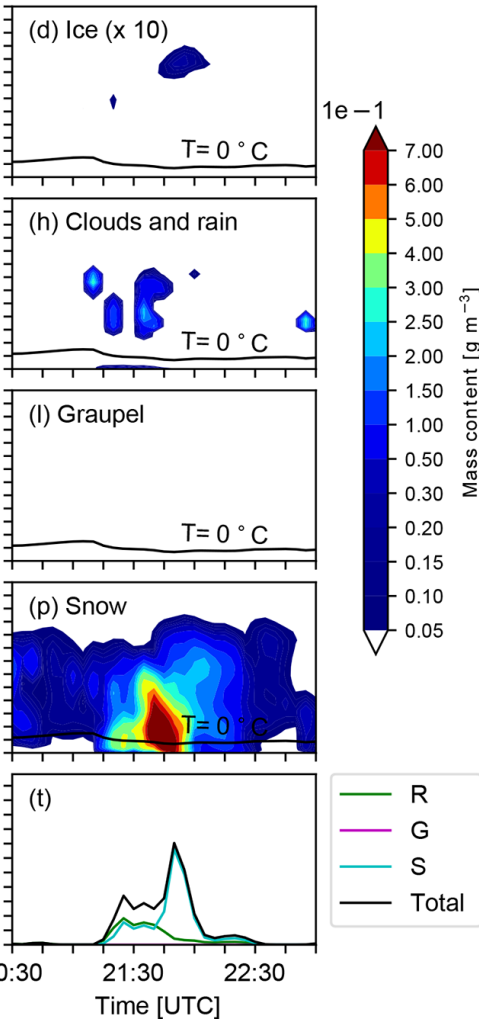

Figure 5. Comparison of the time evolution of hydrometeor mass content $\left(\mathrm{g} \mathrm{m}^{-3}\right)$ at the surface and aloft at KES during the four simulations conducted for CTR, NO_MLT, NO_SBL, and NO_GRPL from left to right. (a-d) are ice-mass content $\left(\times 10 \mathrm{~g} \mathrm{~m}^{-3}\right),(\mathbf{e}-\mathbf{h})$ are clouds and rain-mass content, where rain is only formed through melting of ice, so it is only present near the surface, (i-l) are graupel-mass content, $(\mathbf{m}-\mathbf{p})$ are snow-mass content, and $(\mathbf{q}-\mathbf{t})$ are the surface precipitation rate of rain $(R)$, graupel $(G)$, and snow $(S)$. The $0{ }^{\circ} \mathrm{C}$ isotherm is indicated by the solid black line in $(\mathbf{a}-\mathbf{p})$. $(\mathbf{a}-\mathbf{p})$ have the same colour scale.

\section{Hydrometeor evolution during the event: CTR versus sensitivity experiments}

The roles of phase changes and of the production of graupel in precipitation amounts and types reaching the surface at KES are investigated by comparing the CTR simulation with sensitivity experiments (NO_MLT; NO_SBL; NO_GRPL). First, for NO_MLT, differences with CTR on the surface precipitation intensity and type at KES are minor (Fig. 6, first and second columns). For example, NO_MLT simulation produces slightly less precipitation than CTR, but the precipitation types and their evolution are similar (Fig. 5q and r). In contrast, the evolution of precipitation intensity and types varies significantly at KES, in comparison with CTR for NO_SBL and NO_GRPL (Fig. 5s and t). The peak in precipitation occurred at the beginning of the event $(\sim$ 21:35 UTC) in the warmer environment (NO_SBL) and later during the event $(\sim 21: 50$ UTC) when no graupel were produced (NO_GRPL). Given these findings, the effects of temperature changes from sublimation and riming on the production and the evolution of precipitation are further investigated.
The time series of the vertical evolution of clouds and precipitation for the CTR and the sensitivity experiments at KES are shown in Fig. 5. The distribution of hydrometeors at KES for NO_MLT (Fig. 5 second column) is similar to the CTR, with very little change in precipitation and cloud distribution. When no temperature change from sublimation is considered (NO_SBL), the timing of precipitation is delayed in comparison to CTR (Fig. 5, third column). In that case, the ice and liquid water clouds (Fig. 5c and g) persist for a longer time period than CTR. Moreover, the top of the ice cloud extends up to $7 \mathrm{~km}$, leading to graupel formation (Fig. $5 \mathrm{k}$ ) at higher elevations compared to CTR (Fig. 5). In NO_SBL, the elevation of the $0{ }^{\circ} \mathrm{C}$ isotherm is higher than CTR because the environmental air is generally warmer (Fig. 5, third column). It produces favourable conditions for ice-phase precipitation to melt into rain before reaching the surface. These statements suggest a link among the maximum precipitation rate at the surface produced in warmer conditions (NO_SBL, Fig. 5, third column) as well as the highest ice crystal mass content aloft (Fig. 5c). For NO_GRPL (Fig. 5, fourth column), ice crystals, cloud droplet, and precipitation distribution aloft, as well as at the 

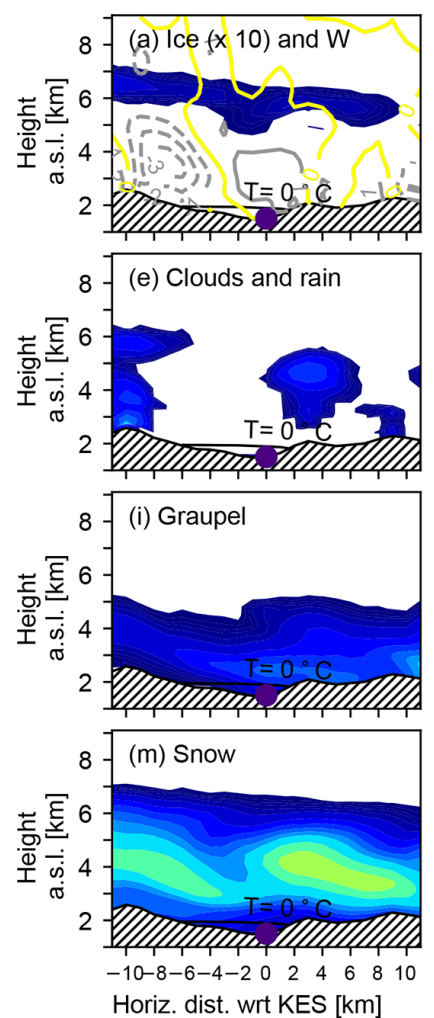
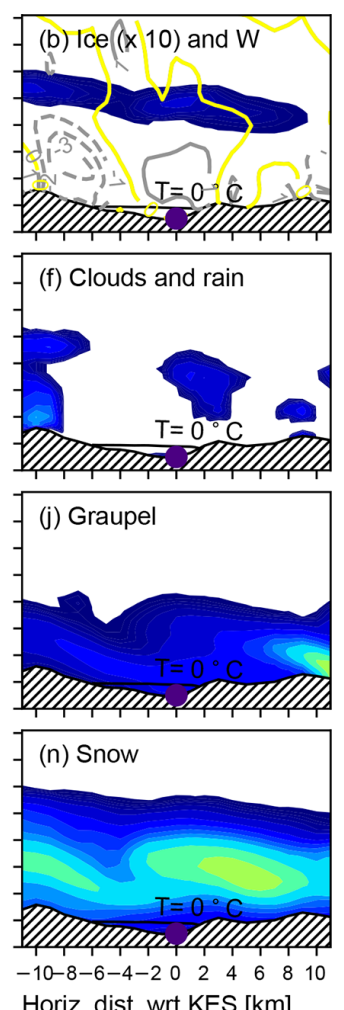
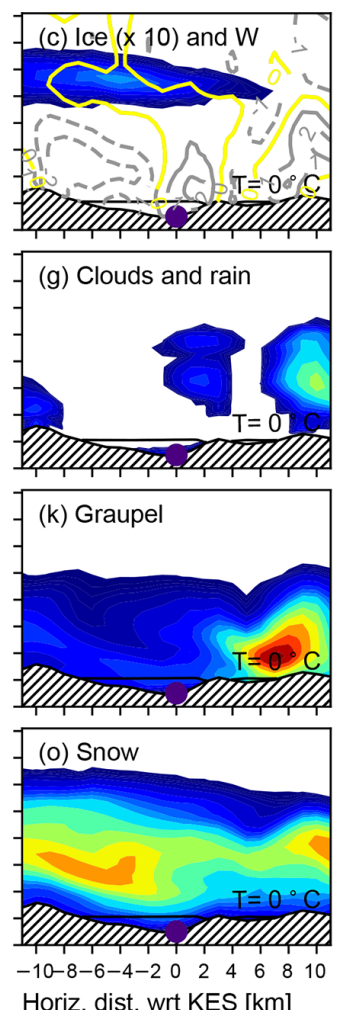
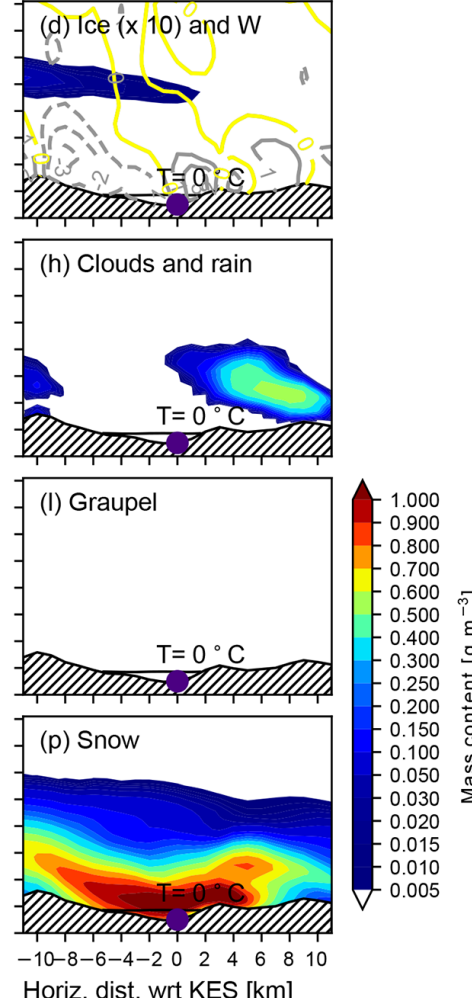

Figure 6. Comparison of the vertical cross section across the Kananaskis Valley along the red line in Fig. 1 showing the mass content of hydrometeors $\left(\mathrm{g} \mathrm{m}^{-3}\right)$ during the four simulations conducted for CTR, NO_MLT, NO_SBL, and NO_GRPL from left to right. (a-d) are ice-mass content $\left(\times 10 \mathrm{~g} \mathrm{~m}^{-3}\right)$ with vertical velocity $\left(\mathrm{m} \mathrm{s}^{-1}\right)$. The yellow line is $0 \mathrm{~m} \mathrm{~s}^{-1}$, the dashed lines are negative values, and the solid lines are positive values, $(\mathbf{e}-\mathbf{h})$ are clouds and rain-mass content, $(\mathbf{i}-\mathbf{l})$ are graupel-mass content, and $(\mathbf{m}-\mathbf{p})$ are snow-mass content. The $0{ }^{\circ} \mathbf{C}$ isotherm is indicated by the solid black line. (a-p) have the same colour scale. The location of KES is indicated by the purple dot.

surface, differs from the counterparts in the CTR simulation (Fig. 5, fourth column). Fewer ice crystals and cloud water mass contents are produced aloft compared to CTR. This could be explained by the lack of warming from accretion resulting in colder temperatures, which leads to less water vapour depositional growth for ice crystals and cloud droplets, and less ice nucleation aloft (e.g. Meyers et al., 1992). Below the ice cloud, fewer cloud droplets are produced for a similar reason. Once graupel are formed, the environmental temperature increases due to the latent heat of fusion from the freezing of cloud droplets. As graupel fall through sub-saturated conditions, they cool the environment because of sublimation, which alters the distribution of hydrometeors aloft (Fig. 5). Finally, in NO_GRPL, the peak in surface precipitation rate (Fig. 5t) is delayed because only relatively slow-falling ice particles such as snowflakes are formed.

The vertical evolution of hydrometeors when snow starts to reach the surface in CTR (21:45 UTC) across the Kananaskis Valley differs for each simulation (Fig. 6). First, for NO_MLT (Fig. 6, second column), no significant difference is observed with CTR simulation for the reason discussed earlier in this section. Second, for NO_SBL (Fig. 6, third column), more rain reaches the surface in the valley because the environmental temperature is higher in comparison to CTR. For NO_SBL, vertical air motions are stronger on the slope east of KES to produce a deep liquid water cloud (Fig. 6c). The ice cloud is also higher and deeper in NO_SBL due to warmer conditions than in CTR (Fig. 6c). The formation of graupel also affects the distribution of cloud and precipitation in the Kananaskis Valley (Fig. 6, fourth column). In NO_GRPL, the ice cloud extends up to KES, but it does not interact with the liquid water cloud, which is formed at lower levels compared to CTR. At this time, the snowfall rate at the surface increases rapidly to reach $3 \mathrm{~mm} \mathrm{~h}^{-1}$ and the rain rate decreases. From Fig. 5, the time series of hydrometeor evolution is completely different for NO_GRPL compared to the other three cases. The cross section at 21:45 UTC (Fig. 6) is not representative of the precipitation onset, but it corresponds to a time when the many types of hydrometeors are simulated aloft. 

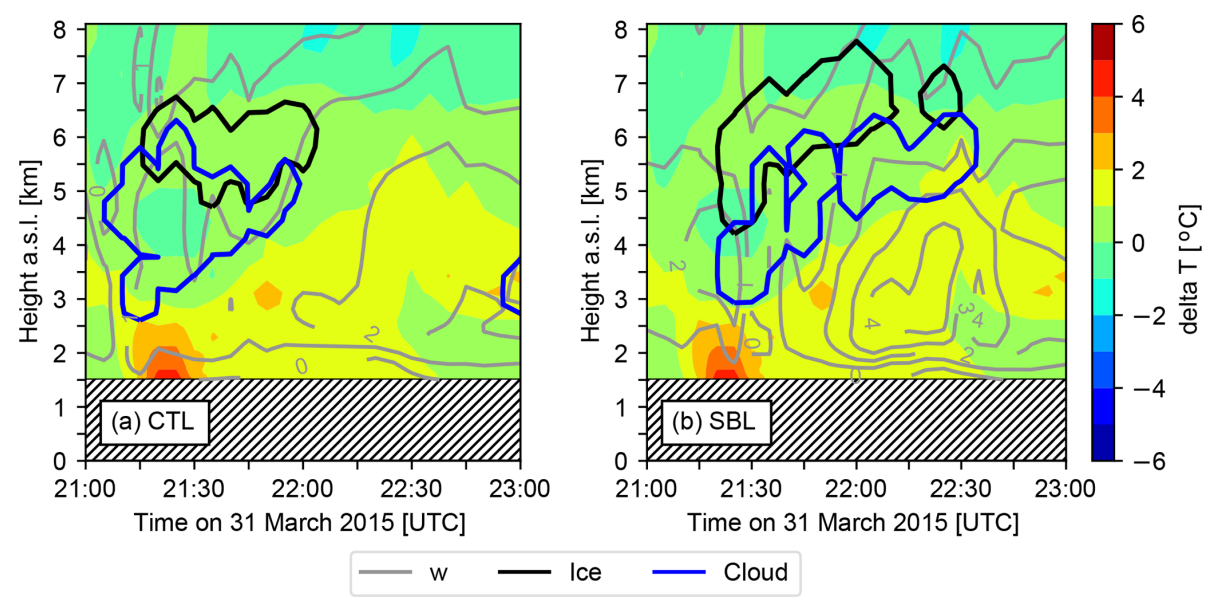

Figure 7. Time series of the vertical air motion ( $w$, grey dashed lines) as well as the contour delimitating water and ice clouds using a minimum threshold of the mass content $\left(5 \times 10^{-3}\right.$ and $5 \times 10^{-4} \mathrm{~g} \mathrm{~m}^{-3}$, respectively) (blue and black line, respectively) are superimposed for (a) CTR and (b) NO_SBL. The temperature difference between the NO_SBL and CTR simulations $(\delta T)$ is added to each panel.

\section{Role of sublimation and snow pellet formation}

This section will assess the role of sublimation and graupel formation in the vertical and horizontal evolution of precipitation intensity and types in the Kananaskis Valley.

First, neglecting the cooling due to sublimation results in higher temperatures at both the surface and aloft (Fig. 7). This higher temperature aloft in the NO_SBL run would increase the amount of snow aloft and at the surface, but only aloft for graupel. As KES is located on the windward side of the Kananaskis Valley, there is generally upward motion at that location. The warmer conditions in NO_SBL produce more instability and, in turn, stronger upward motion. This upward motion leads to thicker and higher ice clouds and liquid water clouds (Fig. 7b). Comparing CTR to NO_SBL (Fig. $5 \mathrm{q}$ and $\mathrm{s}$ ) shows that the maximum precipitation occurs at the beginning of the event for CTR. Warmer conditions in NO_SBL delay the onset of precipitation because of subsaturated conditions aloft. Once the clouds are formed, precipitation reaches the surface at higher rates at KES because less is being transported eastward. The higher rain rate is due to a higher melting level aloft allowing for complete melting of ice-phase precipitation before reaching the ground.

Second, graupel formation impacts the surface precipitation intensity and types, in particular by indirectly influencing the wind flow in the valley. For the CTR case, the evolution of the horizontal wind speed between the onset of the precipitation and the end of the precipitation event (Fig. 8a and d) shows that the direction and magnitude of the wind speed change at the end of the precipitation event in the valley close to KES on the western slope. For NO_GRPL, this wind shear on the windward side of the mountain is suppressed (Fig. 8c and f), whereas it is maintained in NO_SBL (Fig. 8b and e) and NO_MLT (not shown) with a smaller magnitude in both cases. This suggests that the cooling from sublimation and/or melting of graupel produces denser air that moves down the mountainside. In CTR and NO_GRPL, snow is produced mainly over the western barrier with respect to KES as shown in Fig. 8a and $\mathrm{c}$ at the onset of precipitation. The snow-mass content suggests that snow is transported downwind between the onset and end of the precipitation event (Fig. 8). The change in the zonal wind speed (Fig. 8a, c, d, and f) prevents snow from falling at KES in CTR (Fig. 5q). As snowflakes fall at low speed (about $1 \mathrm{~m} \mathrm{~s}^{-1}$ ), their trajectories are strongly dependent on the prevailing horizontal wind field. Since easterly winds were up to $2 \mathrm{~m} \mathrm{~s}^{-1}$ at 22:00 UTC in the CTR, very little snow reaches the surface at KES (Fig. 5q). In NO_GRPL, snow reaches the surface (Fig. 5t) because the downslope flow is weaker than in CTR. Note that in the warmer environment (NO_SBL), the flow reversal is weaker than in the colder one (CTR) but stronger than without snow pellet formation (NO_GRPL). Hence, in the warmer environment (NO_SBL), the deviation of the snow-mass content is not as pronounced as in the colder environment. Furthermore, snowflakes fall much more slowly than graupel (up to 4 times) and will tend to more closely follow streamlines as compared to graupel. This is a possible explanation for the difference in the surface precipitation intensity and types at KES (Fig. 5q-t) and across the Kananaskis Valley (Fig. 8g-i). Moreover, in NO_GRPL, fewer cloud droplets are produced (Fig. 5) over KES. This is probably due to the lack of warming feedbacks from the production of graupel that is considered in CTR. Due to less sublimation occurring above KES in NO_GRPL, the change in the valley flow field is not as strong as in CTR. This leads to more orographic forcing in NO_GRPL, producing the clouds aloft. In this case, the amount of snow produced above KES is negligible because snow produced aloft is advected downwind. Therefore, snow reaching KES is mainly formed on the western barrier with respect to KES. The precipitation is 
(a) CTR 21:00 UTC

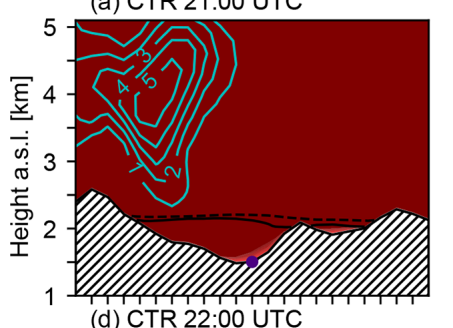

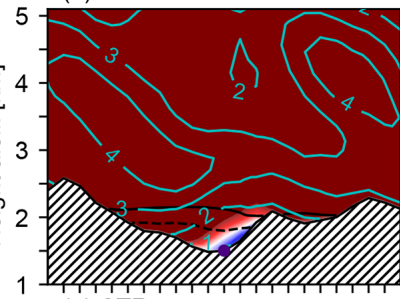
(g) CTR

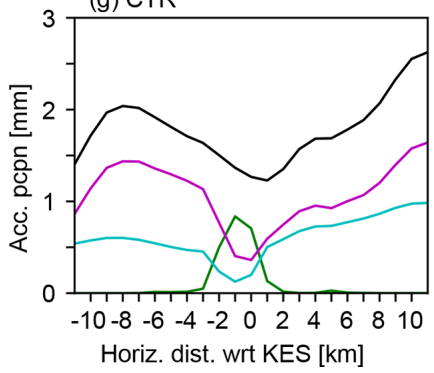

(b) NO_SBL 21:00 UTC

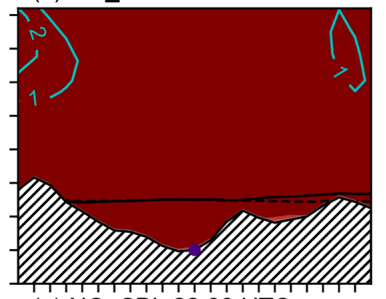

(e) NO_SBL 22:00 UTC

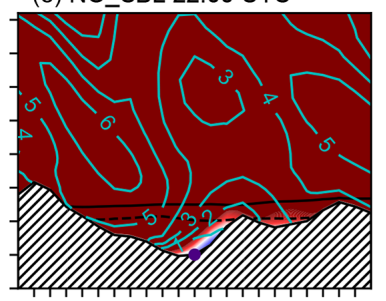

(h) NO_SBL

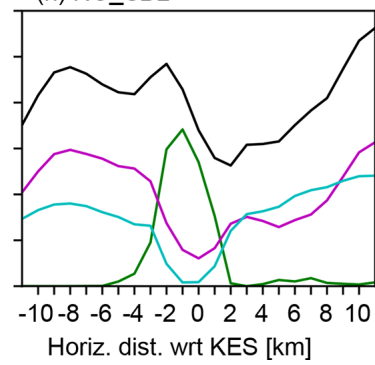

(c) NO_GRPL 21:00 UTC
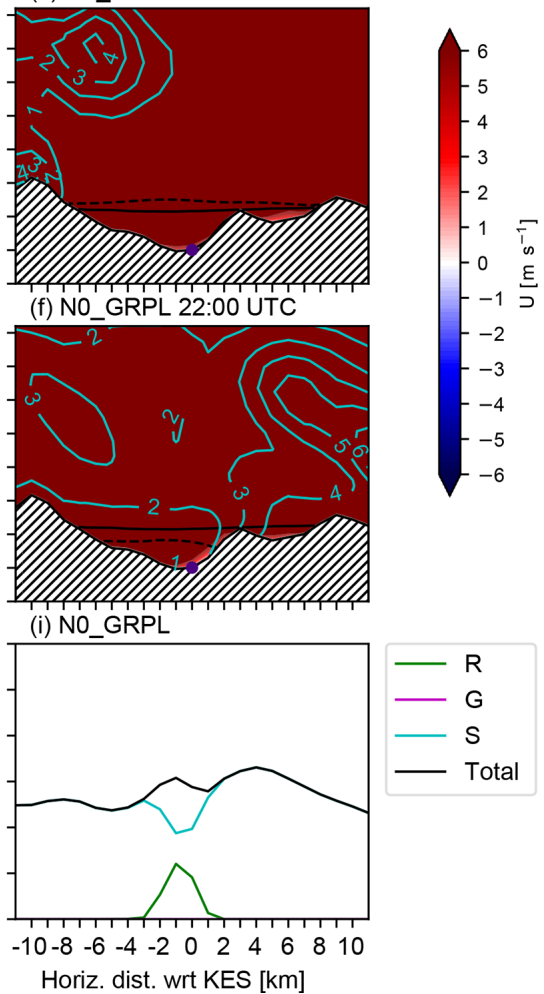

Figure 8. Vertical cross section across the Kananaskis Valley showing the snow field $\left(\times 10 \mathrm{~g} \mathrm{~m}^{-3}\right.$ blue lines) and zonal wind speed (colour shading) at (a-c) 21:00 UTC and (d-f) 22:00 UTC as well as (g-i) the accumulated precipitation during the event along the cross section for $(\mathbf{a}, \mathbf{d}, \mathbf{g})$ CTR simulation, (b, e, h) NO_SBL simulation, and $(\mathbf{c}, \mathbf{f}, \mathbf{i})$ NO_GRPL simulation. The solid black line indicates the location of the $0{ }^{\circ} \mathrm{C}$ isotherm at the onset of precipitation and the black dashed line is the $0{ }^{\circ} \mathrm{C}$ isotherm at the time of the analysis (21:00 and 22:00 UTC). The shaded area is the topography. The negative (positive) wind speed values are easterly (westerly) winds.

transported downwind to KES. This explains why the peak in precipitation rate occurs at later times near the end of the event for NO_GRPL (Fig. 5t).

Finally, given that the trajectories of ice-phase precipitation differ among NO_SBL, CTR, and NO_GRPL, the latent heating profiles also differ. The trajectories of precipitation particles can explain why more cooling from sublimation occurs in NO_GRPL than CTR. Snow would come from the western barrier and the sublimation would occur along the trajectories, while simulations with faster-falling particles would lead to sublimation aloft in the Kananaskis Valley, closer to KES. Note that no lateral shift of the precipitation has been observed between the simulations because the accumulated precipitation is comparable among the runs, but the timing is different (Fig. 8g-i).

\section{Summary and conclusions}

\subsection{Summary}

During the Alberta Field Project (Thériault et al., 2018), snow was often observed at surface temperatures $>0{ }^{\circ} \mathrm{C}$ at the KES observation site. In general, precipitation occurred during relatively dry conditions. For example, ice-phase precipitation was reported at the surface at temperatures up to $9{ }^{\circ} \mathrm{C}$ with a relative humidity of $45 \%$. Also, $60 \%$ of the particles observed were rimed (Hung, 2017). Given these findings, the relative impact of sublimation and melting of hydrometeors, as well as the role of graupel formation, have been investigated. These are addressed by simulating a precipitation event associated with rain and mixed precipitation at the surface, which occurred on 31 March 2015, using the WRF model.

Based on the simulations, a conceptual model explaining the processes leading to the observed precipitation distribution at KES is proposed in Fig. 9. The temperature variations from phase changes impacted the precipitation type, intensity, and its temporal evolution at the surface. The warm conditions of this observed event led to unstable air and resulted in stronger upward motion over a deeper layer. This produced a deep and high ice cloud with liquid water clouds below it. Graupel formed at the top of the liquid cloud and fell rapidly to the surface. At that time, the snow produced on the western barrier is being transported eastward by the wind. The down-valley flow produced by the diabatic cooling from 


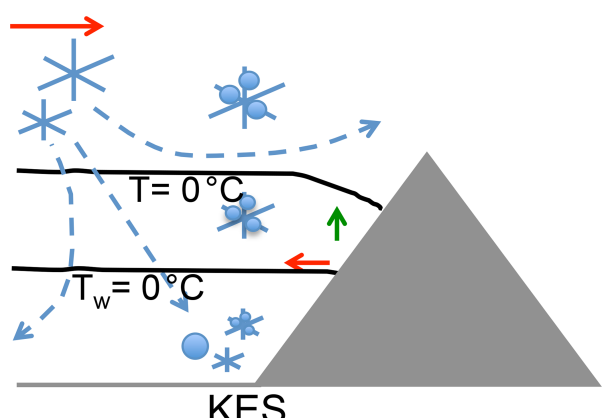

Legend
Raindrop* Snow $*$ Graupel
Trajectories Horizontal wind Vertical wind

Figure 9. Conceptual model explaining the processes driving the evolution of precipitation in the Kananaskis Valley, Alberta. The black solid lines are the $0^{\circ} \mathrm{C}$ air temperature $(T)$ and the wet-bulb temperature $\left(T_{\mathrm{W}}\right)$. The grey area is the terrain.

sublimation prevents the snow from reaching KES because it falls at around $1 \mathrm{~m} \mathrm{~s}^{-1}$. The decrease in mass content is probably associated with a combination of the sublimation of snow and a change in its trajectory associated with the convergence of the flow field produced by the down-valley flow near the valley floor and the westerly flow aloft. This downslope flow is mainly due to the cold and dense air produced by sublimation. The orographic forcing during the precipitation is weaker because of the strength of the downslope wind.

It is important to note here that the CTR simulation was rerun with the Thompson et al. (2008) bulk microphysics scheme. This simulation also shows the presence of strong wind shear at KES towards the end of the event. Less snow reached the surface at that time as well (not shown). The results are consistent with our goal to use the model as an analysis tool of physical processes. However, the graupel and snow fields aloft are different as the production of graupel depends strongly on the parameterization of the conversion from snow to graupel, and it is different in Thompson et al. (2008) and Milbrandt and Yau (2005b). First, Thompson et al. (2008) follow Berry and Reinhardt (1974), and Milbrandt and Yau (2005b) follow Murakami (1990), for which the conversion of snow to graupel depends on the collection and the vapour deposition. Second, note that the mass converted into graupel also depends on the assumed size distribution of snow, which is an inverse exponential in Milbrandt and Yau (2005b) but is different in Thompson et al. (2008). In addition, the more recent cloud microphysics scheme called the Predicted Particle Properties (P3, Morrison and Milbrandt, 2015) allows smooth transitions in the riming degree, which produces a more realistic transition between snow, partially rimed snow, and graupel. Finally, relative saturated atmospheric conditions would lead to a weaker wind shear that could let the snow reach KES. Further investigation should be conducted on this.

The parameterization of graupel formation and evolution could affect the amount and distribution of precipitation at the surface. This study shows that rimed-faster-falling particles and unrimed-slow-falling particles (snow) reaching KES will not be formed at the same location aloft. The CTR produces a small amount of snow at the surface. Given that the conversion to graupel occurred in certain conditions, snow remained aloft longer, which altered the graupel formation and its vertical evolution. This suggests that the amount of graupel may be underestimated. Even if this is the case, it would not change the physical processes highlighted in Fig. 9 about the sublimation of snow and graupel and the presence of graupel aloft. It can, however, alter the amount of the different types and timing of precipitation reaching the surface depending on the amount of snow conversion into graupel.

\subsection{Conclusions}

Based on the results obtained from the simulations and the conceptual model, key conclusions are as follows.

- The model reproduces well the atmospheric conditions and the precipitation amounts and type.

- Sublimation has a greater impact than melting on the evolution of the precipitation at the surface. This is due to the sub-saturated conditions in the lower atmosphere, which decreases the atmospheric layer where ice-phase precipitation can melt.

- When the thermodynamic impact of sublimation is not considered, it alters the environmental temperature aloft. The warmer conditions create more upward motion, which leads to favourable conditions for accretion (graupel formation) aloft. Furthermore, it allows for a warmer melting layer near the surface resulting in a higher proportion of rain.

- As the precipitation falls and is transported by the wind, it alters the distribution of latent heating due to phase changes, and this, in turn, affects the wind direction along the mountainside.

- The trajectories of particles explain some of the differences in the precipitation amounts and types distribution at KES. Snowflakes fall slower than graupel, and therefore they tend to more closely follow streamlines. For example, snow reaching the surface at KES is produced on the westward side of the Kananaskis Valley.

- The relative amount of snow reaching KES depends on the strength of the vertical wind shear above KES. Stronger down-valley flow will tend to prevent snow particles from reaching KES. 
This study has some limitations. First, due to some instrumentation issues, the measurements of wind speed and wind direction during the Alberta Field Project were sometimes inconsistent. Second, this study also has some numerical limitations due to the choice of microphysics parameterization in the WRF and to the specific surface module in the WRF for instance. Different microphysics schemes would produce different precipitation rates and thus affect the cooling rate associated with sublimation and melting. In a dry environment with temperatures near $0^{\circ} \mathrm{C}$, if snowflakes do not sublimate, it can overestimate the amount of precipitation produced in models, leading to warm biases. Furthermore, the rate of autoconversion from snow to graupel will also impact the distribution of precipitation aloft and, in turn, at the surface. This is particularly important in complex terrain as previously mentioned in Milbrandt et al. (2009) and Morrison et al. (2015). Using another cloud microphysics scheme, however, should not qualitatively modify results. Similar conclusions on involved physical processes in the distribution and types of hydrometeors at the surface would be obtained. Other atmospheric conditions should be further investigated. A relatively more saturated environment would lead to different results, for instance, a weaker vertical wind shear in a case of weak precipitation. In that case, graupel/snow particles do not sublimate and will melt. The diabatic cooling by melting would be reduced, which could allow particles to reach KES. Third, simulations using a particle-tracking model could be used to compute the trajectories of the precipitation particles to better assess the environmental conditions in which they fall.

Overall, this study shows that the microphysical processes leading to precipitation in complex terrain could significantly impact the precipitation intensity and type in the valley. Even if the study is conducted based on a relatively light precipitation event, critical scientific insights on the formation and evolution of precipitation are gained. Accurate representations of precipitation phase changes and accretion leading to graupel, as well as the wind field, are critical, in particular in sub-saturated orographic regions such as the eastern slopes of the Canadian Rockies.

Data availability. The dataset used to conduct this study is available upon request to the corresponding author (Julie M. Thériault). These are the Weather and Research Forecasting (WRF) simulations, the necessary information and files to conduct the simulations.

Author contributions. EP conducted the simulations, did some analysis, and wrote most of the paper. JMT designed the simulations. JMT and ML contributed scientifically through the data analysis. Finally, all the authors contributed scientifically by providing comments and suggestions.
Competing interests. The authors declare that they have no conflict of interest.

Special issue statement. This article is part of the special issue "Understanding and predicting Earth system and hydrological change in cold regions". It is not associated with a conference.

Acknowledgements. We would like to thank the Natural Sciences and Engineering Research Council of Canada (NSERC), Global Water Futures, as well as Canadian Research Chair in Extreme Winter Weather Events for providing support to accomplish this work. One of the authors (Émilie Poirier) would like to thank the Fond Quebecois de la recherche sur la nature et les technologies (FRQNT) and NSERC for graduate scholarships.

Financial support. This research has been supported by Natural Sciences and Engineering Research Council of Canada (NSERC) Discovery Grants (grant nos. 418374-2012-RGPIN and 201906654-RGPIN) and the NSERC, Climate Change and Atmospheric Research, Changing Cold Regions Network (grant no. 4339232012).

Review statement. This paper was edited by Chris DeBeer and reviewed by three anonymous referees.

\section{References}

Barth, M. C. and Parsons, D. B.: Microphysical processes associated with intense frontal rainbands and the effect of evaporation and melting on frontal dynamics, J. Atmos. Sci., 53, 1569-1586, 1996.

Battaglia, A., Rustemeier, E., Tokay, A., Blahak, U., and Simmer, C.: PARSIVEL snow observations: A critical assessment, J. Atmos. Ocean. Tech., 27, 333-344, 2010.

Berry, E. X. and Reinhardt, R. L.: An Analysis of Cloud Drop Growth by Collection Part II. Single Initial Distributions, J. Atmos. Sci., 31, 1825-1831, https://doi.org/10.1175/15200469(1974)031<1825:AAOCDG>2.0.CO;2, 1974.

Burford, J. and Stewart, R. E.: The sublimation of falling snow over the Mackenzie River Basin, Atmos. Res., 49, 289-314, 1998.

Clough, S. A. and Franks, R. A. A.: The evaporation of frontal and other stratiform precipitation, Q. J. Roy. Meteorol. Soc., 117, 1057-1080, 1991.

Fabry, F. and Zawadzki, I.: Long-term radar observations of the melting layer of precipitation and their interpretation, J. Atmos. Sci., 52, 838-851, 1995.

Fargey, S., Hanesiak, J., Stewart, R., and Wolde, M.: Aircraft observations of orographic cloud and precipitation features over southern Baffin Island, Nunavut, Canada, Atmos. Ocean, 52, 54-76, 2014.

Ferrier, B. S.: A double-moment multiple-phase four-class bulk ice scheme, Part I: Description, J. Atmos. Sci., 51, 249-280, 1994. 
Harder, P. and Pomeroy, J.: Estimating precipitation phase using a psychrometric energy balance method, Hydrol. Process., 27, 1901-1914, 2013.

Henson, W., Stewart, R., and Hudak, D.: Vertical reflectivity profiles of precipitation over Iqaluit, Nunavut during Autumn 2007, Atmos. Res., 99, 217-229, 2011.

Hong, S.-Y., Noh, Y., and Dudhia, J.: A new vertical ciffusion package with an explicit treatment of entrainment processes, Mon. Weather Rev., 134, 2318-2341, 2006.

Hung, I.: Characteristics and formation of precipitation over the kananaskis characteristics and formation of precipitation over the Kananaskis Emergency Site during March and April 2015, MS thesis, University of Manitoba, Manitoba, 2017.

Iacono, M. J., Delamere, J. S., Mlawer, E. J., Shephard, M. W., Clough, S. A., and Collins, W. D.: Radiative forcing by long-lived greenhouse gases: Calculations with the AER radiative transfer models, J. Geophys. Res.-Atmos., 113, D13103, https://doi.org/10.1029/2008JD009944, 2008.

Ishizaka, M., Motoyoshi, H., Nakai, S., Shiina, T., Kumakura, T., and Muramoto, K.: A new method for identifying the main type of solid hydrometeors contributing to snowfall from measured size-fall speed relationship, J. Meteorol. Soc. Jpn., 91, 747-762, 2013.

Kain, J. S.: The Kain-Fritsch convective parameterization: An update, J. Appl. Meteor., 43, 170-181, 2004.

Klugmann, D., Heinsohn, K., and Kirtzel, H. J.: A low cost $24 \mathrm{GHz}$ FM-CW Doppler radar rain profiler, Contrib. Atmos. Phys., 69, 247-253, 1996.

Liu, A. Q., Mooney, C., Szeto, K., Thériault, J. M., Kochtubajda, B., Stewart, R. E., Boodoo, S., Goodson, R., Li, Y., and Pomeroy, J.: The June 2013 Alberta catastrophic flooding event: Part 1 - Climatological aspects and hydrometeorological features, Hydrol. Process., 30, 4899-4916, 2016.

Marwitz, J. D.: The kinematics of orographic rirflow during Sierra Storms, J. Atmos. Sci., 40, 1218-1227, 1983.

Marwitz, J. D.: Deep Orographic Storms over the Sierra Nevada. Part I: Thermodynamic and Kinematic Structure, J. Atmos. Sci., 44, 159-173, 1987.

Matrosov, S. Y., Battaglia, A., and Rodriguez, P.: Effects of Multiple Scattering on Attenuation-Based Retrievals of Stratiform Rainfall from CloudSat, J. Atmos. Ocean. Tech., 25, 2199-2208, 2008.

Matsuo, T., Sasyo, Y., and Sato, T.: Relationship between types of precipitation on the ground and surface meteorological elements, J. Meteorol. Soc. Jpn., 59, 462-476, 1981.

Mesinger, F., DiMego, G., Kalnay, E., Mitchell, K., Shafran, P. C., Ebisuzaki, W., Jović, D., Woollen, J., Rogers, E., Berbery, E. H., Ek, M. B., Fan, Y., Grumbine, R., Higgins, W., Li, H., Lin, Y., Manikin, G., Parrish, D., and Shi, W.: North American Regional Reanalysis, B. Am. Meteorol. Soc., 87, 343-360, 2006.

Meyers, M. P., DeMott, P. J., and Cotton, W. R.: New primary icenucleation paramterizations in an explicit cloud model, J. Clim. Appl. Meteorol., 31, 708-721, 1992.

Milbrandt, J. A. and Yau, M. K.: A multi-moment bulk microphysics parameterization. Part I: Analysis of the role of the spectral shape parameter, J. Atmos. Sci., 62, 2051-3064, 2005a.

Milbrandt, J. A. and Yau, M. K.: A Multimoment Bulk Microphysics Parameterization. Part II: A Proposed Three-Moment
Closure and Scheme Description, J. Atmos. Sci., 62, 3065-3081, 2005b.

Milbrandt, J. A., Yau, M. K., Mailhot, J., and Bélair, S.: Simulation of an Orographic Precipitation Event during IMPROVE-2. Part I: Evaluation of the Control Run Using a Triple-Moment Bulk Microphysics Scheme, Mon. Weather Rev., 136, 3873-3893, 2009.

Milrad, S. M., Gyakum, J. R., and Atallah, E. H.: A meteorological analysis of the 2013 Alberta flood: Antecedent large-scale flow pattern and synoptic-dynamic characteristics, Mon. Weather Rev., 143, 2817-2841, 2015.

Minder, J. R., Durran, D. R., and Roe, G. H.: Mesoscale controls on the mountainside snow line, J. Atmos. Sci., 68, 2107-2127, 2011.

Morrison, H. and Milbrandt, J. A.: Parameterization of Cloud Microphysics Based on the Prediction of Bulk Ice Particle Properties. Part I: Scheme Description and Idealized Tests, J. Atmos. Sci., 72, 287-311, 2015.

Morrison, H., Milbrandt, J. A., Bryan, G. H., Ikeda, K., Tessendorf, S. A., and Thompson, G.: Parameterization of Cloud Microphysics Based on the Prediction of Bulk Ice Particle Properties. Part II: Case Study Comparisons with Observations and Other Schemes, J. Atmos. Sci., 72, 312-339, 2015.

Murakami, M.: Numerical modeling of dynamical and microphysical evolution of an isolated convective cloud - The 19 July 1981 CCOPE cloud, J. Meteorol. Soc. Jpn., 68, 107-128, 1990.

Parker, D. J. and Thorpe, A. J.: The role of snow sublimation in frontogenesis, Q. J. Roy. Meteorol. Soc., 121, 763-782, 1995.

Poirier, E.: Étude de la ligne pluie-neige dans la vallée de Kananaskis, Alberta, MS thesis, Universite du Quebec a Montreal, Quebec, 2017.

Pomeroy, J. W., Stewart, R. E., and Whitfield, P. H.: The 2013 flood event in the South Saskatchewan and Elk River basins: Causes, assessment and damages, Can. Water Resour. J., 41, 105-117, 2016.

Rasmussen, R., Baker, B., Kochendorfer, J., Meyers, T., Landolt, S., Fischer, A. P., Black, J., Thériault, J. M., Kucera, P., Gochis, D., Smith, C., Nitu, R., Hall, M., Ikeda, K., and Gutmann, E.: How Well Are We Measuring Snow: The NOAA/FAA/NCAR Winter Precipitation Test Bed, B. Am. Meteorol. Soc., 93, 811829, 2011.

Skamarock, W. C. and Klemp, J. B.: A time-split nonhydrostatic atmospheric model for weather research and forecasting applications, J. Comput. Phys., 227, 3465-3485, 2008.

Steiner, M., Bousquet, O., Houze Jr., R. A., Smull, B. F., and Mancini, M.: Airflow within major Alpine river valleys under heavy rainfall, Q. J. Roy. Meteorol. Soc., 129, 411-431, 2003.

Stewart, R. E., Burford, J. E., Hudak, D. R., Currie, B., Kochtubajda, B., Rodriguez, P., and Liu, J.: Weather systems occurring over Fort Simpson, Northwest Territories, Canada, during three seasons of 1998-1999: 2. Precipitation features, J. Geophys. Res., 109, 1-19, 2004.

Tewari, M., Chen, F., Wang, W., Dudhia, J., LeMone, M., Mitchell, K., Ek, M., Gayno, G., Wegiel, J., and Cuenca, R.: Implementation and verification of the unified NOAH land surface model in the WRF model, in: Proceedings of the 20th Conference on Weather Analysis and Forecasting/16th Conference on Numerical Weather Prediction, Seattle, USA, 12-15 January 2004, 11$15,2004$. 
Thériault, J. M., Rasmussen, R., Smith, T., Mo, R., Milbrandt, J. A., Brugman, M. M., Joe, P., Isaac, G. A., Mailhot, J., and Denis, B.: A case study of processes impacting precipitation phase and intensity during the Vancouver 2010 Winter Olympics, Weather Forecast., 27, 1301-1325, 2012.

Thériault, J. M., Rasmussen, K. L., Fisico, T., Stewart, R. E., Joe, P., Gultepe, I., Clément, M., and Isaac, G. A.: Weather observations on Whistler Mountain during five storms, Pure Appl. Geophys., 171, 129-155, 2014.

Thériault, J. M., Milbrandt, J. A., Doyle, J., Minder, J. R., Thompson, G., Sarkadi, N., and Geresdi, I.: Impact of melting snow on the valley flow field and precipitation phase transition, Atmos. Res., 156, 111-124, 2015.
Thériault, J. M., Hung, I., Vaquer, P., Stewart, R. E., and Pomeroy, J. W.: Precipitation characteristics and associated weather conditions on the eastern slopes of the Canadian Rockies during March-April 2015, Hydrol. Earth Syst. Sci., 22, 4491-4512, https://doi.org/10.5194/hess-22-4491-2018, 2018.

Thompson, G., Field, P. R., Rasmussen, R. M., and Hall, W. D.: Explicit Forecasts of Winter Precipitation Using an Improved Bulk Microphysics Scheme. Part II: Implementation of a New Snow Parameterization, Mon. Weather Rev., 136, 5095-5115, https://doi.org/10.1175/2008MWR2387.1, 2008.

Zängl, G.: Reversed flow in the south-Alpine Toce Valley during MAP-IOP 8: Further analysis of latent cooling effects, Q. J. Roy. Meteorol. Soc., 133, 1717-1729, 2007. 